\title{
Penentuan Masak Fisiologi dan Ketahanan Benih Kenikir (Cosmos caudatus Kunth) terhadap Desikasi
}

\author{
Determination of Physiological Maturity and Dessication Tolerance \\ of Cosmos caudatus Kunth Seed \\ Muhammad Abdul Rahman Hakim ${ }^{1}$ dan M. Rahmad Suhartanto ${ }^{\text {* }^{*}}$ \\ Diterima 1 Mei 2015 / Disetujui 2 Juli 2015
}

\begin{abstract}
Cosmos caudatus Kunth is an annual herb useful for natural herbal medicine especially for reducing body odour and improving apetite. The leaves are edible vegetable. Research was conducted in Unit of Conservation and Biofarmaka Cultivation (UKBB) and Seed Technology Laboratory at the Department of Agronomy and Horticulture in Bogor Agricultural University between December 2013 until April 2014. The purpose of this research was to determine the period of physiological maturity and to study the resistance of Cosmos caudatus Kunth seed to dessication. The first stage of this research used completely randomized design with 1 factor and 5 different levels of harvest period : 24 days, 28 days, 32 days, 36 days, 40 days. The second stage of research used completely randomized design with 2 factors, i.e. drying method and time. The drying methods used were of 2 types : drying in box dryer (fan and heater) at $37-41{ }^{\circ} \mathrm{C}$ and $\mathrm{RH} 29-38 \%$, and in box dryer (fan) at $28-32{ }^{\circ} \mathrm{C}$ and $\mathrm{RH} 34-44 \%$. There were 5 variations of drying time $(1,2,3,4$ and 5 hours) for drying in box dryer (fan and heater) and box dryer (fan). The first stage research revealed that seed physiological maturity could be determined from the suitable harvest period of 40 days prior to blooming, while the second stage research showed that the effective drying time was 2-3 hours, and box dryer (fan) or wind drying gave a better drying result than that of box dryer (fan and heater).
\end{abstract}

Keywords : Box dryer, Natural herbal medicine, Seed harvest period.

\begin{abstract}
ABSTRAK
Kenikir merupakan tanaman herba semusim yang berguna sebagai obat herbal alami serta dapat dikonsumsi sebagai sayuran pada bagian daunnya. Percobaan dilaksanakan di Kebun Percobaan Unit Konservasi dan Budi Daya Biofarmaka dan Laboratorium Teknologi Benih Departemen Agronomi dan Hortikultura, Institut Pertanian Bogor pada bulan Desember 2013 hingga April 2014. Tujuan penelitian adalah menentukan periode masak fisiologi benih kenikir dan mempelajari ketahanan benih terhadap desikasi. Penelitian pertama menggunakan rancangan acak lengkap 1 faktor dengan 5 perlakuan periode umur panen : 24 hari, 28 hari, 32 hari, 36 hari, dan 40 hari. Penelitian kedua menggunakan rancangan acak lengkap 2 faktor yaitu dengan metode pengeringan dan waktu pengeringan. Metode pengeringan terdiri atas 2 taraf perlakuan yaitu pengeringan dengan menggunakan alat box dryer (fan and heater) dengan suhu $37-41{ }^{\circ} \mathrm{C}$, RH $29-38$ $\%$ dan box dryer (fan) dengan suhu $28-32{ }^{\circ} \mathrm{C}$, RH $34-44 \%$ sedangkan waktu pengeringan terdiri atas 5 taraf perlakuan $(1,2,3,4,5)$ jam untuk pengeringan menggunakan box dryer (fan and heater) dan menggunakan box dryer (fan). Penelitian pertama menunjukkan hasil bahwa penentuan masak fisiologi benih kenikir dapat dilihat dari umur panen yang sesuai pada saat masak fisiologi 40 hari sebelum berbunga dan hasil penelitian kedua menunjukkan bahwa waktu pengeringan yang efektif adalah 2-3 jam serta pengeringan menggunakan box dryer (fan) atau kering angin lebih baik dibandingkan dengan menggunakan box dryer (fan dan heater).
\end{abstract}

Kata kunci : box dryer, obat herbal alami, umur panen benih

\footnotetext{
${ }^{1}$ Departemen Agronomi dan Hortikultura, Fakultas Pertanian, Institut Pertanian Bogor

(Bogor Agricultural University), Jl. Meranti, Kampus IPB Darmaga, Bogor 16680, Indonesia

Telp.\&Faks. 62-251-8629353.*Email korespondensi: tantosuhartanto12@yahoo.co.id
} 


\section{PENDAHULUAN}

Sayuran indigenous merupakan sayuran asli daerah yang telah banyak diproduksi dan dikonsumsi oleh masyarakat di suatu daerah tertentu. Sayuran indigenous yang terdapat di daerah Jawa Barat adalah kenikir, kemangi, poh-pohan, kecipir/jaat, oyong, gambas/emes, labu, koro/roay, dan sebagainya (Rachman et al., 2002). Sayuran ini biasanya ditumbuhkan di pekarangan rumah atau di kebun sehingga dapat dimanfaatkan untuk kepentingan keluarga, seperti dimasak menjadi sayur atau dimakan mentah (lalaban). Selain digunakan untuk konsumsi, sayuran indigenous juga dapat dimanfaatkan untuk kesehatan dan tanaman hias karena bunganya yang indah. Sayuran ini umumnya dibudidayakan masyarakat dalam skala kecil dan bersifat lokal. Tanaman indigenous juga mempunyai resistensi yang tinggi terhadap patogen dan mudah beradaptasi dengan lingkungan yang kurang baik, sehingga dapat dimanfaatkan sebagai pengganti sayuran komersial dalam pemenuhan kebutuhan nutrisi manusia (Chen, 1999).

Salah satu sayuran indigenous yang berpotensi sebagai pengganti sayuran komersial dalam pemenuhan kebutuhan manusia adalah kenikir. Kenikir (Cosmos caudatus Kunth) merupakan salah satu jenis sayuran indigenous yang berasal dari famili Compositae dan genus Cosmos. Kenikir merupakan tanaman herba semusim atau tahunan, berbatang tegak dengan tinggi mencapai $3 \mathrm{~m}$. Batangnya berbentuk segi empat, beralur, bercabang banyak, dan berwarna hijau keunguan. Daun kenikir majemuk, bersilang berhadapan, bentuk menyirip, ujung runcing, tepi rata, berwarna hijau tua pada bagian permukaan atas dan berwarna lebih terang, serta sedikit berambut pada permukaan bawah daun. Pembungaan kenikir terletak di ujung atas tanaman. Panjang tangkai bunga sekitar 5-30 $\mathrm{cm}$, mahkota bunga terdiri atas 8 helai dengan panjang $1.5-2 \mathrm{~cm}$, dan berwarna kuning. Benih kenikir berwarna cokelat dan berbentuk seperti jarum dengan ujung berambut (van den Bergh, 1994). Tanaman kenikir diperbanyak dengan menggunakan biji. Persemaian biji dapat dilakukan langsung di lapangan atau di pembibitan terlebih dahulu. Pembibitan dilakukan sekitar 3 minggu kemudian dapat dipindahtanamkan di lahan dengan jarak antar tanam $25 \mathrm{~cm} \times 30 \mathrm{~cm}$. Penambahan pupuk organik 10 ton ha ${ }^{-1}$ dan urea $200 \mathrm{~kg} \mathrm{ha}^{-1}$ pada tanah miskin hara dapat diberikan untuk meningkatkan hasil panen dan meningkatkan kualitas daun. Pengaturan air yang baik sangat penting bagi pertumbuhan kenikir (van den Bergh, 1994).

Pengembangan kenikir sebagai sayuran indigenous diperlukan benih bermutu. Salah satu cara memperoleh benih yang bermutu dan berkualitas baik ialah dengan penentuan waktu panen secara tepat. Penentuan waktu panen yang baik dapat membantu memenuhi keperluan benih, baik kuantitas maupun kualitas. Keperluan benih dari segi kuantitas dapat diperoleh dengan waktu pemanenan yang cepat, sehingga kebutuhan benih dapat tercapai dan permintaan terhadap benih kenikir dapat terpenuhi. Sementara itu, kualitas benih yang baik dapat diketahui jika benih sudah mencapai masak fisiologi. Kadar air merupakan salah satu tolok ukur yang menentukan benih tersebut sudah mencapai masak fisiologi. Peningkatan produksi dapat dilakukan salah satunya dengan penggunaan benih hibrida yang mempunyai produktivitas tinggi (Harliani et al., 2014). Benih dengan kadar air masih yang tinggi harus diuji dengan pengujian kadar air agar diketahui kelompok benih tersebut tergolong benih rekalsitran, intermediet, atau ortodoks. Benih rekalsitran dan intermediet jika terkena matahari langsung terlalu lama akan mengurangi daya simpan benih dan benih akan cepat rusak atau mati. Benih ortodoks tergolong benih yang memiliki kadar air rendah dan cenderung tahan terhadap radiasi matahari serta memiliki daya simpan benih yang cukup panjang. Oleh karena itu, pengujian desikasi perlu dilakukan agar diketahui benih kenikir tetap memiliki viabilitias tinggi, sehingga benih kenikir yang bermutu dan berkualitas baik dapat dihasilkan dan dikomersialkan. Penelitian ini bertujuan menentukan periode masak fisiologi benih kenikir dan mempelajari ketahanan benih terhadap desikasi

\section{BAHAN DAN METODE}

Percobaan dilaksanakan di kebun percobaan Unit Konservasi dan Budidaya Biofarmaka (UKBB) dan Laboratorium Teknologi Benih, Departemen Agronomi dan Hortikultura, Institut Pertanian Bogor pada bulan Desember 2013 hingga April 2014. 
Bahan yang digunakan dalam percobaan ini adalah benih kenikir dengan tingkat umur panen yang berbeda, alat tulis, label, kertas stensil, dan aquades. Alat yang digunakan adalah oven, alat pengecambah benih Germinator IPB 72 I, alat pengepres kertas merang IPB 75 I, desikator yang digunakan sebagai alat pendingin untuk benih yang diuji.

Percobaan I dilakukan untuk menentukan masak fisiologi benih kenikir. Percobaan I pada penentuan masak fisiologi benih kenikir akan mendapatkan umur panen benih yang optimum melalui proses pertumbuhannya sehingga akan diperoleh informasi mengenai waktu masak fisiologi benih kenikir yang paling tepat dengan melihat pertumbuhan benih kenikir yang terjadi. Benih diperoleh dari kebun Unit Konservasi dan Budidaya Biofarmaka (UKBB) Cikabayan, Bogor. Rancangan percobaan yang digunakan adalah Rancangan Acak Lengkap (RAL) 1 faktor yang terdiri atas 5 taraf : 24, 28, 32, 36, 40 hari sebelum berbunga (HSB). Setiap perlakuan dilakukan 3 ulangan. Penelitian dimulai dengan pelabelan benih yang dilakukan setiap 4 hari sekali sejak muncul kuncup bunga. Kenikir dipanen secara serempak pada waktu panen yang ditentukan. Benih dipilah berdasarkan umur panen yang kemudian dibersihkan dari sisa-sisa kelopak bunga yang kering dan langsung dilakukan pengujian untuk penentuan masak fisiologi. Benih kenikir berdasarkan umur panen disimpan di dalam botol kaca yang dilapisi plastik atau solatip agar kedap udara. Tahap terakhir ialah pengujian dan pengamatan benih. Peubah yang diamati meliputi pengujian bobot kering (BK), kadar air (KA), daya berkecambah (DB), indeks vigor (IV), dan kecepatan tumbuh $\left(\mathrm{K}_{\mathrm{CT}}\right)$. Data hasil pengamatan diuji dengan menggunakan uji-F dan jika berpengaruh nyata maka dilakukan dengan uji lanjut Duncan Multiple Range Test (DMRT) pada taraf $\alpha=5 \%$.

Percobaan II dilakukan untuk mempelajari sifat benih mengenai ketahanan benih kenikir terhadap desikasi. Percobaan II pada ketahanan benih kenikir terhadap desikasi akan mendapatkan waktu pengeringan yang sesuai dan metode pengeringan yang baik pada benih kenikir. Waktu pengeringan yang tepat dapat memberikan informasi mengenai berapa lama pengeringan yang diperlukan pada benih kenikir. Selain itu, dengan menggunakan metode pengeringan dapat diketahui apakah benih kenikir tahan desikasi, sehingga dapat dikelompokkan menjadi benih rekalsitran, intermediet, atau ortodoks. Percobaan dilakukan dengan pengumpulan benih kenikir sebagai bahan pengujian, sehingga diperoleh benih kenikir untuk pengujian ketahanan benih kenikir terhadap desikasi. Kegiatan yang dilakukan dengan cara pengeringan benih. Percobaan menggunakan Rancangan Acak Lengkap (RAL) 2 faktor yaitu dengan metode pengeringan dan waktu pengeringan. Metode pengeringan terdiri atas 2 taraf perlakuan yaitu pengeringan dengan menggunakan alat box dryer (fan and heater) dengan suhu $37-41{ }^{\circ} \mathrm{C}$, RH 29-38\% dan box dryer (fan) dengan suhu 28-32 ${ }^{\circ} \mathrm{C}$, RH 34-44 \%, sedangkan waktu pengeringan terdiri atas 5 taraf perlakuan $(1,2$, $3,4,5)$ jam untuk pengeringan menggunakan box dryer (fan and heater) dan menggunakan box dryer (fan). Pengamatan yang dilakukan ialah kadar air, viabilitas, dan vigor pada benih kenikir serta Suhu dan RH pada alat box dryer.

Data hasil pengamatan diuji dengan menggunakan uji-F dan jika berpengaruh nyata maka dilakukan dengan uji lanjut Duncan Multiple Range Test (DMRT) pada taraf $\alpha=5 \%$.

\section{HASIL DAN PEMBAHASAN}

\section{Kondisi Umum}

Penanaman dilakukan pada saat musim hujan. Tanaman kenikir yang digunakan sebanyak 30 dan 5 tanaman digunakan sebagai cadangan jika tanaman kenikir mati. Pada fase vegetatif beberapa tanaman kenikir mati. Hal tersebut disebabkan karena adanya hama dan penyakit serta musim hujan yang mengakibatkan kondisi tanaman layu dan busuk. Hama yang menyerang diantaranya adalah semut dan ulat, penyakit yang menyerang adalah layu daun pada tanaman kenikir.

\section{Penentuan Masak Fisiologi Benih Kenikir}

Berdasarkan tolok ukur pada Tabel 1, umur panen berpengaruh sangat nyata pada semua variabel. Viabilitas benih (DB) dan Vigor benih (IV dan KCT) maksimum diperoleh dari benih yang dipanen pada 40 HSB. Kadar air benih pada 40 HSB adalah $10 \%$, dimana kadar air benih kenikir memiliki persentase paling rendah dan kondisi fisik benih yang kering. Bobot kering maksimum 
pada benih kenikir dapat diperoleh pada umur panen benih 36 dan $40 \mathrm{HSB}$.

Daya berkecambah merupakan tolok ukur viabilitas absolut yang mensimulasi viabilitas potensial. Benih dapat berkecambah pada semua tingkat kemasakan yang dilihat dari umur panen, hanya saja terjadi perbedaan daya berkecambah antara tingkat kemasakan dari umur panen benih tersebut. Perbedaan itu antara lain disebabkan karena cadangan makanan yang terdapat pada benih yang belum masak masih belum cukup tersedia bagi pertumbuhan embrio, lain halnya pada benih yang telah masak. Copeland dan McDonald (2001) menyatakan bahwa benih yang telah masak fisiologis mempunyai cadangan makanan sempurna sehingga dapat menunjang pertumbuhan kecambah. Benih yang memiliki daya berkecambah tinggi berarti memiliki bobot kering benih yang tinggi pula. Menurut Justice dan Bass (1994) kemasakan benih merupakan saat dimana bobot kering maksimum tercapai.

Pemanenan lebih baik dilakukan pada saat benih masih dalam kondisi masak fisiologis, karena apabila ditunda atau terlalu cepat, maka kapasitas perkecambahan benih yang dihasilkan akan menurun. Namun beberapa teori umumnya mengaitkan adanya perubahan kondisi fisiologi selama proses pematangan benih seperti dalam hal penurunan kadar air, ketersediaan enzim dan aktivitas metabolism yang dapat meningkatkan ataupun menurunkan kemampuan benih untuk berkecambah (Salisbury dan Ross, 1992).

Vigor benih adalah kemampuan benih tumbuh menjadi tanaman normal dan berproduksi normal dalam keadaan suboptimum. Indeks vigor dan kecepatan tumbuh merupakan tolok ukur dari vigor, dimana indeks vigor dapat dilihat dari perbandingan antara jumlah kecambah normal pada hitungan pertama dengan jumlah seluruh benih yang ditanam. Kecepatan tumbuh dapat diukur dengan jumlah tambahan perkecambahan setiap hari atau etmal pada kurun waktu perkecambahan kondisi optimum (Sadjad, 1993). Menurut Sadjad (1999) nilai kecepatan tumbuh yang tinggi menunjukkan benih tersebut memiliki vigor yang tinggi, mampu berkecambah cepat pada waktu yang relatif lebih singkat dibandingkan dengan benih yang kurang vigor akan berkecambah normal pada jangka waktu yang lebih panjang. Umur pemanenan benih yang berbeda merupakan salah satu faktor dari kondisi lingkungan perkembangan benih. Menurut Copeland dan McDonald (2001) faktor-faktor yang mempengaruhi vigor benih adalah kondisi lingkungan selama perkembangan benih, kondisi genetik benih, dan lingkungan penyimpanan. Kondisi lingkungan perkembangan benih meliputi kelembaban, kesuburan tanah, dan umur pemanenan benih.

Kadar air benih merupakan salah satu faktor yang mempengaruhi umur panen untuk kebutuhan penyimpanan benih. Menurut Justice dan Bass (2002) kandungan benih dipengaruhi oleh kemampuan benih dalam menahan dan menyerap uap air. Kemampuan benih menahan dan menyerap uap air setiap benih berbeda tergantung ketebalan dan struktur kulit benih serta komposisi kimia dalam benih. Menurut Utomo (2006) kandungan kadar air benih 10$20 \%$ pada waktu pemanenan adalah normal pada kebanyakan benih. Benih yang belum masak fisiologi mempunyai kandungan air sangat tinggi mencapai $30-40 \%$.

Tabel 1. Hasil nilai tengah dan sidik ragam pengaruh umur panen $(\mathrm{P})$ terhadap kadar air, bobot kering, viabilitas benih, dan vigor benih kenikir

\begin{tabular}{lccccc}
\hline \multicolumn{7}{c}{ Nilai Tengah } \\
\hline Umur Panen (HSB) & DB $(\%)$ & IV $(\%)$ & $\mathrm{K}_{\mathrm{CT}(\% \mathrm{KN} / \text { trmal })}$ & $\mathrm{KA}(\%)$ & BK (\%) \\
\hline 24 Hari (P5) & $5.3 \mathrm{e}$ & $1.3 \mathrm{~d}$ & $1.4 \mathrm{e}$ & $56.4 \mathrm{~d}$ & $0.4 \mathrm{~d}$ \\
28 Hari (P4) & $27.3 \mathrm{~d}$ & $3.3 \mathrm{~d}$ & $6.2 \mathrm{~d}$ & $49.2 \mathrm{~d}$ & $0.5 \mathrm{c}$ \\
32 Hari (P3) & $49.3 \mathrm{c}$ & $21.3 \mathrm{c}$ & $13.5 \mathrm{c}$ & $17.2 \mathrm{c}$ & $0.8 \mathrm{~b}$ \\
36 Hari (P2) & $65.3 \mathrm{~b}$ & $30.0 \mathrm{~b}$ & $17.9 \mathrm{~b}$ & $11.9 \mathrm{~b}$ & $0.9 \mathrm{a}$ \\
40 Hari (P1) & $80.0 \mathrm{a}$ & $47.3 \mathrm{a}$ & $23.2 \mathrm{a}$ & $10.1 \mathrm{a}$ & $0.9 \mathrm{a}$ \\
\hline Umur Panen (P) & $* *$ & $* *$ & $* *$ & $* *$ & $* *$ \\
\hline
\end{tabular}

Keterangan: HSB : Hari Sebelum Berbunga ; ${ }^{a}$ angka yang diikuti $* *$ : berpengaruh sangat nyata pada taraf $1 \%$ pada tiap baris, $\mathrm{DB}=$ Daya berkecambah; $\mathrm{IV}=$ Indeks vigor; $\mathrm{K}_{\mathrm{CT}}=$ Kecepatan tumbuh; $\mathrm{KA}=$ Kadar air; $\mathrm{BK}=$ Bobot kering. 


\section{Ketahanan Benih terhadap Desikasi}

Berdasarkan data pada Tabel 2-4 dapat diketahui waktu pengeringan memberikan pengaruh sangat nyata terhadap DB, sedangkan waktu pengeringan berpengaruh tidak nyata terhadap IV, $\mathrm{K}_{\mathrm{CT}}$, dan $\mathrm{KA}$. Metode pengeringan memberikan pengaruh sangat nyata pada semua variabel kecuali KA. Interaksi yang terjadi antara waktu pengeringan dengan metode pengeringan memberikan pengaruh tidak nyata terhadap semua variabel.

Persentase daya berkecambah berkaitan dengan persentase kadar air menurut penelitian I, daya berkecambah yang tinggi memiliki kadar air yang rendah. Benih yang digunakan untuk penelitian desikasi adalah benih dengan kadar air awal (10\%) dan telah mencapai masak fisiologi yang memiliki daya berkecambah $80 \%$. Hasil penelitian ini menunjukkan bahwa waktu pengeringan yang paling baik adalah waktu pengeringan 2-3 jam untuk mencapai viabilitas potensial (DB) 64\% ( 2 jam) dan 65\% (3 jam). Pengeringan yang terlalu lama dapat merusak jaringan embrio benih atau cadangan makanan. Menurut Chai et al. 1998 pengeringan atau proses penurunan kadar air dapat meningkatkan viabilitas benih, tetapi pengeringan yang mengakibatkan kadar air yang terlalu rendah akan mengurangi viabilitas benih.
Hal tersebut disebabkan oleh proses pengeringan dengan suhu tinggi yang mengakibatkan jaringan embrio benih atau cadangan makanan menjadi rusak. Hasil penelitian menunjukkan suhu pada metode K1 lebih tinggi dibanding metode K2.

Menurut Boyd dan Deluouche (1990) suhu pengeringan yang optimal untuk pengeringan benih tidak lebih dari $45{ }^{\circ} \mathrm{C}$. Pada benih yang minyak tinggi seperti kacang tanah dan kedelai, dianjurkan suhu pengeringan dan $\mathrm{RH}$ masing-masing tidak lebih dari $37{ }^{\circ} \mathrm{C}$ dan $45 \%$.

Indeks vigor dan kecepatan tumbuh pada metode pengeringan $\mathrm{K} 2$ lebih tinggi dibandingkan metode K1. Hal ini dikarenakan metode K2 memiliki persentase daya berkecambah lebih tinggi dibandingkan metode K1 (Tabel 4). Vigor benih mencapai maksimum pada saat masak fisiologi. Viabilitas akan menurun seiring waktu dan dalam waktu pendek daya kecambah serta vigor juga menurun. Benih yang memiliki vigor rendah akan berakibat terjadinya kemunduran benih yang cepat selama penyimpanan, makin sempitnya keadaan lingkungan dimana benih dapat tumbuh, kecepatan berkecambah menurun, kepekaan akan serangan hama dan penyakit meningkat, meningkatnya jumlah kecambah abnormal, dan rendahnya produksi tanaman.

Tabel 2. Rekapitulasi sidik ragam pengaruh waktu pengeringan dan metode pengeringan terhadap kadar air, viabilitas benih, dan vigor pada desikasi benih kenikir ${ }^{a}$

\begin{tabular}{lcccc}
\hline \multirow{2}{*}{ Perlakuan } & \multicolumn{4}{c}{ Tolok Ukur } \\
\cline { 2 - 5 } & $\mathrm{IV}(\%)$ & $\mathrm{DB}(\%)$ & $\mathrm{K}_{\mathrm{CT}(\% \mathrm{KN} / \text { etmal })}$ & $\mathrm{KA}(\%)$ \\
\hline Waktu Pengeringan & tn & $* *$ & tn & tn \\
Metode Pengeringan & $* *$ & $* *$ & $* *$ & tn \\
P x K & tn & tn & tn & tn \\
\hline
\end{tabular}

Keterangan: ${ }^{a}$ tanda yang diikuti $*$ : berpengaruh nyata pada taraf 5\%; $* *$ : berpengaruh sangat nyata pada taraf $1 \%$; tn : berpengaruh tidak nyata pada taraf $5 \% . \mathrm{IV}=$ Indeks vigor; $\mathrm{DB}=$ Daya berkecambah; $\mathrm{K}_{\mathrm{CT}}=$ Kecepatan tumbuh; KA= Kadar air.

Tabel 3. Pengaruh waktu pengeringan $(\mathrm{P})$ terhadap kadar air, viabilitas, vigor pada desikasi benih kenikir $^{\mathrm{a}}$

\begin{tabular}{ccccc}
\hline \multirow{2}{*}{ Waktu Pengeringan } & \multicolumn{4}{c}{ Nilai Tengah } \\
\cline { 2 - 5 } & IV $(\%)$ & DB $(\%)$ & $\mathrm{K}_{\mathrm{CT}(\% \text { KN/tmal })}$ & KA (\%) \\
\hline 1 jam & 18.7 & $53.7 \mathrm{~b}$ & 14.3 & 7.4 \\
jam & 17.3 & $64.0 \mathrm{a}$ & 16.8 & 7.6 \\
3 jam & 20.7 & $65.0 \mathrm{a}$ & 17.5 & 5.0 \\
5 jam & 20.0 & $53.0 \mathrm{~b}$ & 14.2 & 7.4 \\
\hline
\end{tabular}

Keterangan: angka-angka pada kolom yang sama yang diikuti oleh huruf yang sama tidak berbeda nyata pada taraf uji $5 \%$ (uji selang berganda Duncan). $\mathrm{IV}=$ Indeks vigor; $\mathrm{DB}=$ Daya berkecambah; $\mathrm{K}_{\mathrm{CT}}=$ Kecepatan tumbuh; KA= Kadar air. 
Tabel 4. Pengaruh metode pengeringan (K) terhadap kadar air, viabilitas, vigor pada desikasi benih kenikir

\begin{tabular}{llccc}
\hline \multirow{2}{*}{ Metode Pengeringan } & \multicolumn{4}{c}{ Nilai Tengah } \\
\cline { 2 - 5 } & IV (\%) & DB (\%) & $\mathrm{K}_{\mathrm{CT}(\% \text { KN/tmal) }}$ & KA (\%) \\
\hline K1 (suhu 37-41 ${ }^{\circ} \mathrm{C}$, RH 29-38\%) & $9.5 \mathrm{~b}$ & $40.1 \mathrm{~b}$ & $10.3 \mathrm{~b}$ & 5.9 \\
$\mathrm{~K} 2$ (suhu 28-32 ${ }^{\circ} \mathrm{C}$, RH 34-44\%) & $29.6 \mathrm{a}$ & $72.5 \mathrm{a}$ & $19.9 \mathrm{a}$ & 8.2 \\
\hline
\end{tabular}

Keterangan: Metode pengeringan K1 : Box dryer (Heater and Fan), K2 : Box dryer (Fan). ${ }^{a}$ angka-angka pada kolom yang sama yang diikuti oleh huruf yang sama tidak berbeda nyata pada taraf uji $5 \%$ (uji selang berganda Duncan). IV= Indeks vigor; $\mathrm{DB}=$ Daya berkecambah; $\mathrm{K}_{\mathrm{CT}}=$ Kecepatan tumbuh; $\mathrm{KA}=$ Kadar air.

Sadjad et al. (1999) mengemukakan bahwa benih yang mempunyai kecepatan tumbuh yang tinggi memiliki tingkat vigor yang tinggi pula. Vigor tinggi dapat dilihat pula dengan hasil viabailitas yang tinggi pula. Umumnya sebagai variabel untuk viabilitas benih digunakan persentase perkecambahan. Dimana perkecambahan harus cepat dan pertumbuhan kecambahnya kuat, dan ini mencerminkan kekuatan tumbuhnya yang dapat dinyatakan dengan laju perkecambahan. Kecepatan tumbuh benih lebih tajam dalam menunjukkan penurunan maupun peningkatan vigor dibandingkan dengan daya berkecambah. Kecepatan tumbuh benih merupakan tolak ukur yang mengindikasikan vigor kekuatan tumbuh. Untuk menilai viabilitas benih, tolok ukur kecepatan tumbuh akan memperlihatkan hasil yang lebih dapat membedakan antar perlakuan metode pengeringan daripada daya berkecambah. Hal ini disebabkan tolok ukur kecepatan tumbuh merupakan tolok ukur untuk menilai kemampuan benih berkecambah pada kondisi yang suboptimum, sedangkan daya berkecambah diuji pada kondisi yang optimum.

\section{KESIMPULAN}

Masak fisiologi benih kenikir dicapai pada umur panen 40 HSB yang ditandai dengan viabilitas, vigor, kadar air $10 \%$ dan bobot kering benih maksimum. Benih kenikir dapat dikeringkan hingga kadar air 5.023 7.619\% dengan menggunakan box dryer (fan) pada suhu $32-35{ }^{\circ} \mathrm{C}$, RH $34-44 \%$.

\section{DAFTAR PUSTAKA}

Agrawal, R.L. 1980. Seed Technology. Oxford and IBTI Publishing Company. 685p. New Delhi (IN).
Boyd, A.H., J.C. Delouche. 1990. Seed Drying Principles. Selected Article on Seed Drying. Seed Technology. Laboratory, Mississippi State University. p 1-20.

Chai, J.R., M.L Li, Y. Du 1998. Optimum moisture contents of seed stored at ambient temperatures. Seed Science Research 8 Supplement. 1: 23-28.

Chen, N. 1999. Evaluating the potential of leafy vegetables, p 86-99. Di dalam: Engle L.M., N.C. Altoveros, editor. Collection, Conservation, and Utilization of Indigenous Vegetable. AVRDC.p 86-99. Taiwan (TW).

Copeland, L.O., M.B. McDonald. 2001. Principles of Seed Science and Technology. Burgess Publishing Company. New York (US).

Harliani, E. N., E. R. Palupi, D. S. Wahyudin. 2014. Potensi penyimpanan serbuk sari dalam produksi benih hibrida mentimun (Cucumis sativus L.) varietas KE014. J. Hort. Indonesia 5(2) : 104-117.

Justice, O.L., L.N. Bass 1994. Prinsip dan Praktek Penyimpanan Benih. Raja Grafindo Persada. Jakarta.

Justice, O.L., L.N. Bass. 2002. Prinsip dan Praktek Penyimpanan Benih. Roesli, R., penerjemah. Rajawali Pr. Terjemahan dari : Principles and Practices of Seed Storage. Jakarta.

Kuswanto, H. 1997. Analisis Benih. Andi Offset. 140p. Yogyakarta.

Kuswanto, H. 2003. Teknologi Pemrosesan, Pengemasan, dan Penyimpanan Benih. Kanisius. Yogyakarta. 
Rachman, S., Suryadi, A.A. Witono, Hidayat, U. Komara. 2002. Identifikasi dan Dokumentasi Diversitas, Nilai Ekonomis, serta Sistem Pengelolaan Sayuran Indigenous. Laporan Kegiatan Penelitian. Balai Penelitian Tanaman Sayuran. Lembang.

Sadjad, S. 1993. Dari Benih kepada Benih. Gramedia Widya Sarana Indonesia. Jakarta.

Sadjad, S. 1994. Kuantifikasi Metabolisme Benih. PT. Gramedia Widya Sarana. Jakarta.

Sadjad, S., E. Murniati, S. Ilyas. 1999. Parameter Pengujian Vigor Benih dari Komparatif ke Simulatif. Grasindo. Jakarta.
Salisbury, F.B. C.W Ross. 1992. Plant Physiology. Wadsworth Publishing Company. California (US).

Sumadi. 2004. Peranan Uji Vigor Benih dalam Peningkatan Produksi Kedelai. Kinerja Penelitian Mendukung Agribisnis Kacang-kacangan dan Umbi-umbian. Pusat Penelitian dan Pengembangan Tanaman Pangan. Bogor.

Utomo. 2006. Ekologi Benih. USU Repository. Medan.

Van den Bergh M.H. 1994. Cosmos caudatus Kunth. Di dalam: Siemonsma J.S, K. Piluek, editor. Plant Resources of South-East Asia. PROSEA (8): Vegetables. p 152-153. Bogor. 